\title{
A REVIEW OF HIV AND AIDS CURRICULAR RESPONSES IN THE HIGHER EDUCATION SECTOR: WHERE ARE WE NOW AND WHAT NEXT?
}

\author{
L. Wood \\ Faculty of Education Sciences \\ North-West University \\ Potchefstroom, South Africa \\ e-mail: lesley.wood@nwu.ac.za
}

\section{Pillay}

Higher Education HIVIAIDS Programme

Universities South Africa

e-mail:managa@usaf.ac.za

\section{ABSTRACT}

Curriculum integration of HIV and AIDS in higher education is a strategic priority of the Higher Education AIDS programme (HEAIDS), yet little progress has been made in this area. To address this, HEAIDS is leading a project aimed at capacitating the development of HIV curriculum initiatives. The purpose of this article is to present a critical overview of internationally published work concerning the integration of HIV and AIDS into the curriculum of higher education, to determine what has been done in terms of integration, to assess what has been evaluated as successful, and to determine what lessons we can draw from it to inform the way forward. A total of 106 sources were identified by conducting key word searches in three main search engines; additional references from these and back issues of leading HIV and AIDS education journals were also consulted. We critically discuss the findings to draw conclusions about best practices concerning theoretical underpinnings, pedagogy and curriculum content. We conclude by highlighting some aspects that can help to inform the infusion of HIV and AIDS into the curricula of higher education in South Africa and beyond.

Keywords: capacity development, critical pedagogy, curriculum integration, HIV and AIDS education, modes of integration, participatory pedagogy

\section{INTRODUCTION}

The Higher Education HIV and AIDS Programme (HEAIDS) was established in recognition of the fact that higher education 'has a critical role to play in the fight against the spread of the disease' (HEAIDS 2008, 3). In addition to policy calling for the prioritisation of prevention interventions by higher education institutions and provision of care and support for faculty and 
students (HEAIDS 2008), curriculum integration is necessary to ensure that graduates develop the skills needed to live and work in a diverse world and are committed to improving society through the skills and knowledge gained from their education. However, to date, there is little evidence that this is happening. Rather, there is more evidence that academics are not making the link between their discipline and the social aspects of HIV and AIDS (De Lange 2014; Wood 2011a), thereby missing how it can be used to deepen student comprehension of the intersectionality of issues that threaten social and economic development.

HEAIDS identified the need for a multi-disciplinary, multi-institutional research project to build capacity of academic staff to integrate HIV and AIDS issues into the curriculum. Before beginning with any research regarding curriculum integration, it thus makes sense to explore what is being done in the Higher Education curriculum in South Africa, what needs to be done and how academics could be supported to do it. The identification of best practices, as well as those that were not so successful, will help to inform the current research endeavour, rendering it more effective, relevant and evidence-based. In this article we report on a desktop analysis of published work concerning the integration of HIV and AIDS into the curriculum of higher education. The various questions that this review will answer include the following:

- What are the various theoretical underpinnings that influence how HIV and AIDS education is viewed and how does this in turn influence how it is conceptualized and integrated at higher education level?

- What successes and challenges have been reported internationally, in Africa and in South Africa?

- What conclusions can be made about integration of HIV and AIDS into higher education curricula in South Africa to inform the next step of the project?

We first explain the methodology used for the literature review, then clarify some of the main concepts, before we turn to the questions.

\section{METHODOLOGY}

Potential articles were sourced by conducting key word searches (HIV and AIDS education and higher education, HIV and AIDS and FET, curriculum integration on HIV and AIDS in higher education and colleges, faculty and HIV and AIDS) in three main search engines: Science Direct, Ebscohost and Google Scholar. References contained in journals sourced from these search engines were consulted to provide more sources. In addition, back issues of the African 
Journal of AIDS Research, South African Journal of Higher Education, South African Journal of Education, AIDS Care and SAHARA (Social Aspects of HIV and AIDS Research) were consulted. Since HIV and AIDS is a fast developing field, only sources dated from 2000 on were considered.

All identified studies were reviewed and grouped according to whether they were South African, African or international examples. Any that did not meet the criteria of being an example of integration into the formal curriculum were then discarded. In total, 106 publications were included. Details of the publications were then entered onto Excel spreadsheets, indicating the exact reference, summary of abstract, model of integration, theoretical underpinnings, curriculum content, curriculum outcomes deemed successful and lessons learnt. Since only published, peer reviewed work was included, we assumed the methodology used to evaluate the specific examples was valid and the findings therefore trustworthy. Saturation of knowledge was judged to have been reached with this number, since repetition was evident. As expected, many of the works cited each other, due to the relative scarcity of work done on integration of HIV and AIDS into the formal curriculum at higher education.

There may be many more unpublished instances of integration which could not be accessed. There also may be courses that address HIV indirectly through topics such as gender, poverty, social justice, etc., but inclusion of these would have necessitated a review on each topic. In addition, only publications containing information about HIV and AIDS content in the formal curriculum (i.e., registered, accredited and fee paying courses) were included, since this is the focus of the project. Consequently, publications on peer education programmes, noncompulsory online HIV and AIDS courses for students and other such programmes were not included.

\section{COMMON MODES OF INTEGRATION FOR HIV AND AIDS INTO THE CURRICULUM AT HIGHER EDUCATION}

There are several terms associated with inclusion of HIV and AIDS into the curriculum which need to be clarified to avoid confusion.

Mainstreaming is defined in various ways (see UNAIDS, the World Bank and UNDP 2005; UNESCO 2008; SIDA 2005) but the common link appears to be that it refers to a sectorwide response to the pandemic of which curriculum integration is only one aspect. Likewise, institutionalising refers to how each institution chooses to respond to the pandemic (Van Wyk and Pieterse 2006), usually framed within an HIV and AIDS policy. In this article, integration 
refers specifically to the inclusion of HIV-related outcomes in the formal curriculum, rather than institution-wide responses. By HIV-related outcomes, we mean learning that promotes a deep and intersectional understanding of the complexity of the pandemic in relation to other issues of injustice and inequality that mitigate against social inclusion and enablement. The formal curriculum comprises both undergraduate and post-graduate programmes, the latter linking curriculum integration closely with research. Curriculum integration moves the response beyond prevention to create a holistic understanding of how HIV manifests in all areas of life and thus has a universal impact on a nation's population.

Integration can be attained by: a stand-alone module on HIV and AIDS; integration into one specific 'carrier' subject; and integration in more than one module or infused throughout the programme. Each of these approaches has advantages and disadvantages as indicated in Table 1. We also acknowledge that integration can take place on several levels, ranging from a superficial, technical level to a multi-layered and more nuanced infusion of HIV that promotes a deeper understanding of disciplinary approaches that foster social inclusivity. However, the focus in the literature tends to be on the kind of model used, rather than the quality of the HIVrelated outcomes.

Table 1: Different models to integrate HIV and AIDS (Wood 2012)

\begin{tabular}{|c|c|c|}
\hline & Advantages & Disadvantages \\
\hline Stand alone module & $\begin{array}{l}\text { Has a legitimate place in } \\
\text { curriculum; can recruit and train } \\
\text { lecturers to act as resource } \\
\text { persons; specific timetabling } \\
\text { allows more aspects of HIV to be } \\
\text { covered; assessment of learning } \\
\text { made easier. }\end{array}$ & $\begin{array}{l}\text { Space needs to be made; new } \\
\text { modules take a long time to } \\
\text { approve; students may not link } \\
\text { relevance of HIV to real life and } \\
\text { other modules; difficult to find } \\
\text { people who specialise in this and } \\
\text { also know faculty specific subject } \\
\text { matter; excludes other } \\
\text { academics from developing } \\
\text { capacity in this regard; may have } \\
\text { a limited biomedical or narrow } \\
\text { professional focus. }\end{array}$ \\
\hline Integrated into carrier subject & $\begin{array}{l}\text { Clear where and when to include } \\
\text { and who is responsible for it; } \\
\text { fewer specialised lecturers } \\
\text { needed; assessment is } \\
\text { facilitated. }\end{array}$ & $\begin{array}{l}\text { Need to decide what to drop to } \\
\text { make time for HIV - may cause } \\
\text { resistance; limited aspects can } \\
\text { be covered; cannot guarantee } \\
\text { faculty assigned to module will be } \\
\text { motivated; may be ignored in } \\
\text { comparison to other learning } \\
\text { outcomes of module. }\end{array}$ \\
\hline Infused into several modules & $\begin{array}{l}\text { Curriculum revision usually not } \\
\text { needed; can cover a wide range } \\
\text { of HIV aspects in different } \\
\text { modules; lecturers complement } \\
\text { each other with knowledge, skills; } \\
\text { sharing of responsibility promotes }\end{array}$ & $\begin{array}{l}\text { Needs careful analysis of existing } \\
\text { curriculum to organise } \\
\text { coherently; It may disappear in } \\
\text { reality when teaching takes } \\
\text { place; many in faculty need to be } \\
\text { trained; sharing of responsibility }\end{array}$ \\
\hline
\end{tabular}




\begin{tabular}{|l|l|l|}
\hline & Advantages & Disadvantages \\
\hline & collaboration; students see the & can become shedding of \\
& relevance of HIV from different & responsibility; assessment more \\
& perspectives; it becomes the & complicated; can result in \\
& responsibility of many. & duplication, omissions. \\
\hline
\end{tabular}

Literature suggests that there is a need to adopt a holistic view of HIV and AIDS in the curriculum, therefore a stand-alone module, if used, needs to be supplemented by some form of curricular infusion at programme level to ensure adequate coverage and avoidance of duplication (Van Wyk and Pieterse 2006; Wood 2011a). In any case, the disadvantages of each model need to be carefully considered and provision made to minimize them. Most importantly, capacity building of academics is crucial to support integration (HEAIDS 2010a). We suspect that models, such as the ones presented above, tend to lead to a techno-rationale approach to integration, with a too narrow disciplinary focus - e.g., one lecture on the legal implications of HIV in the workplace - rather than HIV serving as a topic that allows disruptive dialogue around how various disciplinary practices and professional attitudes and behaviour might work for or against social inclusivity and enablement. We now turn to addressing the research questions guiding this review.

\section{THEORETICAL FRAMEWORKS INFORMING CURRICULAR RESPONSES TO HIV AND AIDS EDUCATION}

It is clear from the literature reviewed that the theoretical lens used to think about HIV and AIDS education influences the way that it is integrated into the curriculum. The choice of theory usually depends on the discipline concerned and the underlying pedagogical theories on which the curriculum was developed. In countries with a low HIV prevalence (e.g., USA, Canada, Australia, Western Europe) a more technical-rational approach to HIV education at tertiary level seems to be the norm, since the main focus is to protect students in their personal capacity, rather than position HIV and AIDS as a social issue (Ergene, Cok, Tumer and Unal 2005). Most of the interventions here focus on behavioural change of students, in terms of primary prevention and reduction of stigmatising attitudes. Some of the common theories that underline such change are: AIDS Risk reduction model (e.g., Fisher and Fisher 2000); Diffusion of Innovation model (e.g., Bertrand 2004); Health Belief Model (e.g., Obregon 2000); Social Cognitive Theory (e.g., Bandura 2004); Stages of Change model (e.g., Munro, Lewin, Smart and Volmink 2007); Theory of Reasoned Action (e.g., Montano and Kasprzyk 2002). These models assume that knowledge leads to behaviour change, ignoring the social and structural barriers to individual change, such as unequal gender relations and incapacitating poverty. Few, 
if any, of these theories are suitable to inform curriculum in South Africa, where HIV is a social issue with a complex aetiology. Sub-Saharan Africa is the epicentre of the pandemic and local knowledge, based on local experiences and interpretations, should serve as the starting point to develop indigenous theories that will diminish the epistemic injustice (Fricker 2007) that seems to exist, judging by the lack of home-grown theories to explain the phenomenon. Epistemic injustice occurs when we buy into the notion that African knowledge is somehow inferior to knowledge from the Global North and so not worthy to be heard (testimonial injustice). This results in difficulty in articulating our experiences (hermeneutic injustice) (Fricker 2007) and only giving credence to theories developed from clinical randomised control trials. In countries where HIV prevalence is of epidemic proportions, a more nuanced and critical approach is preferred, based on knowledge developed from our lived experiences of the social, cultural, historical and political complexities of the disease.

Within the South African literature, there is strong support for a critical approach to HIV and AIDS education that positions it as a social justice and developmental issue (e.g., Baxen and Wood 2013; Francis 2010; Morrell 2003; Semali 2006; Wood 2012). Such a paradigm recognises the complexity of the pandemic and acknowledges that there are no uniform and final solutions. It advocates continual disruption of existing ideologies and structures, an approach that requires the critical thinking that is expected at higher education level (Elkana 2009). Graduates who will fill professional and/or leadership roles in society would benefit from education about the discriminatory political, social, economic and health practices within and across their disciplines that create fertile terrain for HIV transmission. HIV and AIDS education is complex, and necessarily touches on almost all aspects of our lives (Abdool Karim, Abdool Karim and Baxter 2010, 45) so if education around the pandemic is framed in a critical paradigm, it can only help to transform higher education programmes to be more relevant to the current South African social, economic and health contexts. From a critical paradigm, HIV and AIDS education finds its place in the curriculum by addressing the causes and consequences of the pandemic - e.g., social justice issues; legal implications; developmental implications; management and workplace issues; social and psychological issues; ethical issues; human rights issues; and health issues. In short, every faculty could find some meaningful link to HIV and AIDS education (Wood 2012) from a disciplinary perspective. HIV and AIDS can also be used as meaningful examples when teaching discipline-related concepts (Craig, Xia and Venter 2004).

\section{CURRICULAR RESPONSES OF HIGHER EDUCATION TO HIV AND AIDS:}




\section{SUCCESSES, CHALLENGES AND IMPLICATIONS FOR THE SOUTH AFRICAN CONTEXT}

A comprehensive survey of the international literature revealed very few examples of curriculum integration. Most of the articles focused on research that supported a need for curriculum integration, rather than reporting on actual work done. Not surprisingly, most of the international publications focused on education for doctors and nurses (Williams, Wang, Burgess, Wu, Gong and Li 2006; Mak and Yui 2010), pharmacists (Balfour, Corace, Tasca, Best-Plummer, MacPherson and Cameron 2010), health care workers (Burr, Storm and Gross 2006), dentists (Giuliani, Tumbarello and Marino et al. 2011; Rohn, Sankar, Hoelscher, Luborsky and Parise 2006; Seacat, Litt and Daniels 2009) and veterinary students (Davis 2008). Situated in low prevalence countries, the focus tended to be on transmitting information relevant to the intended profession, and/or the reduction of stigma (Burr et al. 2006; Rohn et al. 2006) to increase empathy towards HIV positive people graduates may come into contact with during their work. Programmes that only transmitted information were not as successful as those that also required students to interact with HIV positive patients (Jafari, Yazdani, Khami, Mohammadi and Hajiabdolbaghi 2012; Seacat et al. 2009). When lectures were supplemented by behavioural components (e.g., role plays) and clinical components (actually interacting with patients) the outcomes were more effective (Mak and Yui 2010; Williams et al. 2006; Zaninovic et al. 2013).

In general, the literature revealed the need for more integration of HIV into social work (Rowan and Shears 2011) and psychology courses (Bristow 2000). Although a comprehensive social work curriculum which incorporated training on how to work more closely with the health professions and raised awareness about the intricate interplay of social, health, cultural, psychological and economic issues that social work clients face as a result of HIV was developed in the West Indies (Sogren, Jones, Nathaniel and Cameron-Padmore 2012), its impact was not evaluated empirically. Another area where the need for HIV and AIDS education was highlighted was in dance education and the performing arts (Risner and Thompson 2005) which are an excellent vehicle for addressing the social justice aspects of HIV and AIDS, such as stigma, gender inequality and homophobia (Douglas, Warwick, Whitty and Aggleton 2000). Knowledge is needed around the physical health, emotional issues and psychological issues that HIV positive performers face, given that up to 50 per cent of male dancers are homosexual, and the high incidence of HIV among this population in the USA (Risner 2002).

Teacher education has perhaps received the most attention in terms of HIV and AIDS 
education, specifically in high prevalence countries, but this has been discussed in depth elsewhere (see HEAIDS 2010a for a concise overview of national/international literature).

In summary, the international literature indicates relatively little published work on curriculum integration at higher education level, probably because of the low incidence of HIV in most of these countries and the fact that it affects mostly minority populations, rather than being a generalised epidemic. In these countries, HIV is mostly regarded as a health issue, and therefore it appears that the health professions have the most need to prepare students to address it in their profession.

In line with international trends, most of the compulsory curriculum integration in African universities tends to have been in the health/medical faculties (Otaala 2006). There are several voluntary courses at institutions which are popular with students as a value-add to their $\mathrm{CV}$ (Association of Commonwealth Universities (ACU) 2001). In most reports on HIV integration into the formal curriculum in African institutions (ACU 2001; Association of African Universities (AAU) 2010; Mugimu and Nabadda 2009; Van Wyk and Pieterse 2006) it was found to be minimal. Stand-alone general compulsory or elective modules for all students seemed to be the norm. However, as the work of McGinty and Mundy (2009) makes clear, students from specific disciplines struggle to make the connection between these and their own field of study and rate them of little significance.

In terms of the above discussion, it therefore appears that curriculum integration is neglected in most African institutions, even although it is highlighted as vital in their respective policies (AAU 2010). Limited access into the academic curriculum was cited as one of the main barriers by the ACU report (ACU 2001) to curriculum integration of HIV and AIDS, as well as lack of leadership and expertise in this regard. The AAU report (2010) states that 48 per cent of tertiary institutions in Africa (South Africa included) are in the process of developing standalone courses in HIV and AIDS; 39 per cent offer a full course in specific disciplines (mostly health related and teaching) and 13 per cent already have stand-alone compulsory courses. These figures are disconcerting, since stand-alone courses are not sufficient to prepare graduates for dealing with the implications of HIV and AIDS in their professional and personal lives (AAU 2010).

With regard to HIV and AIDS integration into carrier modules in specific disciplines, the report indicates some progress in this regard, especially the integration of discipline related issues such as gender, development, migration and child and family wellness through an HIV lens. There have been isolated attempts by faculty members in various disciplines to integrate, but this interest tends to stem from either personal experience with HIV or research connections 
(Chilisa, Bennell and Hyde 2001; Tamale 2012). The ACU report concludes, however:

The ad-hoc model is wide spread and is known to be fast gaining ground. In every higher institution, individual teachers (having gained improved awareness of the magnitude of the threat of the epidemic) are introducing HIV and AIDS issues into their courses. What is needed is for this unconscious energy to be fully harnessed and harmonized for systematic development of formal HIV and AIDS curricula in higher institutions (ACU 2010, 26).

The limited number of articles produced on this topic in the rest of Africa testifies to the lack of curriculum integration, apart from in teacher education (Mugimu and Nabadda 2009). Most of the articles discuss the need for HIV and AIDS integration, often with evidence to show the lack of student/faculty knowledge, but few actually describe what is being done and what effect it is having. Many of the articles make recommendations, but few of these are based on empirical research.

The HEAIDS (2010b) research report of best practices at South African Higher Education Institutions (HEIs) did not reveal much progress in terms of curriculum integration, apart from stand-alone modules for all students, outside of disciplinary curricula (e.g., UCT, Me and AIDS module). This report stressed there was little integration into the curriculum to prepare students to become HIV competent graduates entering the workplace (see HEAIDS 2010b). What is being done is dependent on the work of 'champions', as most academics remain either unconvinced of the need to integrate, or think they lack the competency. Training of academics is thus vital but this will not happen without the support of leadership at institutional and faculty level.

Lesko (2007) conducted a case study at the University of Kwa-Zulu Natal to ascertain how HIV was being integrated across faculties. She concluded that there were two main approaches - technical managerial and interdisciplinary-activist. She advocated that the latter approach to HIV and AIDS education is appropriate to help faculty/students rethink the assumptions, beliefs and stereotypes that divide our society and promote stigma. Lecturers who viewed HIV and AIDS as a social justice issue were able to integrate it across a variety of courses which addressed discourses, theories, actions, attitudes and knowledge. When HIV and AIDS are aligned with these views, it helps to transform the curriculum to bring it more in line with the reality of South African society. The techno-managerial approach resulted in compulsory, stand-alone modules that only focused on prevention, stigma and how to work with HIV in a professional setting, situating it as a health problem and thus missing out on its transformative potential. The development of the capacity of faculty to integrate, and the provision of funds to support such development is thus much needed (Cairns, Dickinson and 
Orr 2006).

The HEAIDS (2010a) report on teacher education made many recommendations as to how integration could be done in Faculties of Education, based on research in 23 universities. This report highlighted that experiential learning and innovative pedagogy enhances student learning. It also stressed the need for choices regarding integration to be made at the curriculum development stage at programme level. The challenges include lack of time and credits, lack of leadership and scarcity of relevant material. An important finding relates to the need to help faculty develop skills to contain their own and student emotions around HIV and AIDS when discussing it in class.

An Advanced Certificate in Education (ACE) HIV and AIDS in teaching was evaluated in 2009 (Wood 2009) as being successful in equipping teachers to take leadership around HIV and AIDS and to integrate it into their teaching and community engagement. However, due to the Department of Basic Education's decision to discontinue bursaries for non-subject-related ACEs, this programme had to be withdrawn. Similarly, HIV and AIDS short-learning programmes are often too expensive for teachers (Holderness 2012). Holderness (2012) concluded that HIV and AIDS education for teachers has to be relevant to the target audience and should focus on reducing stigma and breaking the silence; that learning should be experiential and context based; and that curricula must also cover care and treatment. Specific HIV and AIDS qualifications can help to build up a pool of HIV and AIDS experts within the teaching profession, but such training has to be accessible and affordable to all. Other innovative pedagogies have been developed with teachers, such as simulation games (Petersen, De Beer and Dunbar-Krige 2011; Wilmot and Fraenkel 2009) which, when supplemented with input on the societal impact of HIV, encourage student reflexivity about their own risk and that of their prospective learners, as well as broadening their perspectives of HIV and AIDS.

Themane and Taole (2013) highlighted the need to adapt the curriculum to suit the sociocultural understandings and psycho-social needs of the students. Participatory and selfreflective methods were advocated as optimal for helping students to make the link between HIV and human behaviour. Wood (2011b) found that a limited five credit weighting in a carrier module left students wanting more in-depth learning on how to integrate HIV into their teaching subjects; how to deal with learners in a school situation; and how to develop learner support material. Since it was only part of one module, students struggled, for example, to make the link between HIV and AIDS and inclusive education or citizenship education. To help students see the relevance of HIV education, it has to be underpinned by pedagogical/curriculum theories (Wilmot and Wood 2012) that emphasise how to link HIV and AIDS to subject-specific 
outcomes and how to design and evaluate learning materials and appropriate teaching strategies for HIV and AIDS. Students in this study requested more opportunities to interact with HIV infected/affected people. It was also noted that counselling services need to be available to students who do such courses, since they arouse many emotions.

Van Laren's work in mathematics education with foundation phase student teachers (Van Laren 2007; 2008; 2012) provides useful insights into how participatory methods such as drawing and metaphor work and self-study methods can be used to integrate a 'soft' topic like HIV and AIDS into a so called 'hard' scientific subject. However, her work was based on research conducted with a small group of volunteer students and it needed to be tested within a module to see how it would work as part of the formal curriculum. Webb and Gripper (2010) found that although education students had higher self-efficacy around teaching about HIV and AIDS after completing an HIV module, they were constrained by cultural and parental factors that prevented them from translating their learning into practice.

Van Laren, De Lange and Tanga (2013) and Wood (2011a) conducted research with faculty (the former only education; the latter across education, economic sciences, engineering, health sciences) to ascertain their views and practices around HIV and AIDS integration. Both found a need for real and virtual learning ecologies around HIV and AIDS across disciplines which could help minimize the fears that faculty experienced, stemming from lack of knowledge, not knowing how to talk about HIV with people who are affected and not being able to handle such an emotive subject. Such fears and lack of knowledge led to integration that tended to be didactic, brief and strictly discipline-related.

In other faculties, there are a few publications reporting on the work of 'champions'. One example is Craig, Xia and Venter (2004) who introduced HIV and AIDS education into the curriculum in the Department of Electric, Electronic and Computer Engineering. Third/fourth year students were given a CD on HIV and AIDS and pre- and post-tests indicated an increase in knowledge and a reduction in stigmatising attitudes. The use of a CD was deemed appropriate for students who prefer to use a computer for learning and working. The students also had to apply a mathematical HIV/AIDS model in a 3rd year control systems course which helped them to understand control engineering concepts which can be applied to many fields.

Health Science students at a medical school interacted directly with HIV positive patients and gave educational workshops in local communities (McLean and Hiles 2005). Small group discussions were facilitated by community members rather than lecturers and this helped students to understand local myths around HIV and to explore sensitive matters applicable to the specific community. Although beneficial for student learning and useful to establish 
networks within the community around HIV education, it is a very expensive method of teaching, since students have to be transported to the community and community members expected to be reimbursed.

In an all-faculty approach, Petersen, Bhagwanjee, Bhana and Mahintsho (2004) developed a programme aimed at reducing high-risk sexual behaviours among tertiary students. Although this was a peer education module, it was integrated into an examinable, credit-bearing first year module. It targeted knowledge, self-awareness and skills development around personal behaviour change. The evaluation found that small group work helped males to make safer sexual choices. It was noted that didactic lectures lead to AIDS fatigue in students and that there is a need to devise curricula that will help students to challenge powerful gendered social norms.

To summarise the responses of HEIs in South Africa, most of the studies found were in teacher education, or health sciences. Very few studies on integration into specific modules were available; again there were more studies that proved the need for HIV education than actual examples.

\section{SO WHAT CONCLUSIONS CAN BE DRAWN TO GUIDE CURRICULUM INTEGRATION IN SOUTH AFRICA?}

It would appear that there is a dire need to increase publications on different approaches to the integration of HIV and AIDS into the curriculum, judging from the limited pool available at the moment. One can assume that many academics are integrating it, but they are not researching it and/or they are not publishing results. This leads to a dearth of evidence-based indigenous theories which take our local context into consideration. Teacher education appears to have done most, closely followed by the health professions where HIV is an important element of their work. The literature consulted on the need for inclusion of HIV and AIDS is convincing and much research has also been done on the various theoretical approaches and paradigms to shape how it should be done. However, publications on how to integrate and what impact it has, appear to be minimal. The following conclusions are based on literature consulted:

In terms of mode of delivery, there is a need to move beyond university-wide stand-alone modules, compulsory or not, that focus solely on prevention and protection of students' own health. Although needed, they are not sufficient and should be supplemented by disciplinespecific HIV and AIDS education. Didactic lectures need to be supported by experiential learning/service learning that allows students to interact with the reality of HIV and AIDS in their own communities/professions. Online modules/e learning open up many opportunities for HIV and AIDS education and this field should be further investigated. No literature could be 
found on the use of social media for HIV and AIDS education at tertiary level, for example.

Regarding curriculum content, HIV and AIDS education is best approached from a critical paradigm that recognises the need to challenge and change social norms, human behaviour, laws, policies and practices in societies impacted by the pandemic. Such an approach would help to transform curricula at higher education to make them more responsive to South African societal needs. Viewed from a holistic perspective, HIV and AIDS education can be integrated into every discipline but this needs to be done at programme level when curricula are being designed to avoid repetition omission of knowledge and skills. Furthermore, content should be relevant to both the discipline and the context in which the students live and work professionals interacting with the public have to be able to deal with constraints imposed by socio-cultural norms around HIV and AIDS and related topics. This highlights the need for an integration approach that does not just 'add' or 'bolt on' HIV outcomes, but considers the whole programme and how HIV is used as a topic to promote transformative learning which fosters social inclusivity by troubling dominant normative assumptions.

The development of faculty is crucial to the success of HIV integration, and should ideally be included in strategic management plans and budgets. Faculty need to be supported to integrate into the various disciplines and to understand the intersectionality of HIV with other pressing social issues. They also have to be able to deal with personal fears about addressing HIV and AIDS and explore personal biases and stereotypical discourses. Because the topic evokes emotional responses in students, some studies suggest the need for faculty to become competent in containing their own emotions and those of students before referral. The integration process is under-researched and several studies suggest a self-study action research approach would be ideal to help faculty develop ways to integrate. This would be facilitated by the establishment of virtual and real learning ecologies for HIV education in higher education, preferably discipline-related.

\section{CONCLUSIONS}

In this article, we have presented what literature regards as the most suitable theoretical lenses for placing HIV and AIDS within the curriculum as a catalyst for transformation. We suggested that there is a lack of empirical evidence about what difference integration of HIV and AIDS education can make to student learning. We also suggested that the current literature, particularly that penned by non-African academics, tends to focus on a technical approach to integration where outcomes around HIV competency are seen as an 'add-on', rather than an integral component of developing graduates who are able to view social issues from a multi- 
positional and inclusive perspective. The various barriers to integration were discussed and several conclusions were drawn to guide the way forward.

We conclude by reiterating our stance that, for academic curricula to prepare students effectively for taking on a leadership role within business, society and their own families that promotes social inclusivity, higher education needs to engage students with such discourses via integration of HIV and AIDS within various disciplines and from differing theoretical standpoints. We live in a turbulent world that requires people to operate from an ontological base of inclusion, democracy and respect for diversity and it is the work of higher education to influence this. The dominance of international literature that suggests how we, in the Global South, should address HIV in higher education, troubles us. Situated at the epicentre of the pandemic, southern African academics should focus on the development of indigenous theories that offer a more contextually and culturally relevant lens through which to interpret the implications of the pandemic for social inclusivity and enablement in higher education curricula. HIV and AIDS is one of the most serious threats to health, family life, economic growth and human development that Africa has ever experienced - if we, as leaders in knowledge creation do not take on this challenge then we are failing in our moral duty to the public that we ultimately serve.

\section{ACKNOWLEDGEMENT}

This article was based on a review commissioned by HEAIDS for the project HIV and AIDS in the Curriculum/DHET-NSF.

\section{REFERENCES}

AAU see Association of African Universities.

Association of African Universities. 2010. The response of higher education institutions in Africa to the HIV and AIDS epidemic. A synthesis of four sub-regional surveys is Sub-Saharan Africa. Accra, Ghana: AAU.

Abdool Karim, S. S., Q. Abdool Karim and C. Baxter. 2010. Overview of the book. In HIV/AIDS in South Africa, ed. S. S. Abdool Karim and Q. Abdool Karim, 45-55. Cape Town: Cambridge University Press.

ACU see Association of Commonwealth Universities.

Association of Commonwealth Universities. 2001. HIV/AIDS: Towards a strategy for Commonwealth universities: Report of the Lusaka workshop. London: ACU.

Balfour, L., K. Corace, G. A. Tasca, W. Best-Plummer, P. A. MacPherson and D.W. Cameron. 2010. High HIV knowledge relates to low stigma in pharmacists and university health science students in Guyana, South America. International Journal of Infectious Diseases 14: 881-887.

Bandura, A. 2004. Health promotion by social cognitive means. Health Education \& Behavior 31(2): 143-164.

Baxen, J. and L. Wood. 2013. Mediating sexuality and HIV and AIDS in schools: Lessons for teacher 
education. In Sexuality, society and pedagogy, ed. D. Francis, 15-28. Bloemfontein, SA: Sun Media.

Bertrand, J. T. 2004. Diffusion of innovations and HIV/AIDS. Journal of Health Communication 9(S1): $113-121$.

Bristow, A. R. 2000. HIV disease in the Psychology curriculum. Teaching of Psychology 27: 98-102.

Burr, C. K., B. S. Storm and E. Gross. 2006. A faculty trainer model: Increasing knowledge and changing practice to improve perinatal HIV prevention and care. AIDS Patient Care and STDs 20(3): 183-192.

Cairns, M., D. Dickinson and W. Orr. 2006. Wits University’s response to HIV/AIDS: Flagship programme or 'tramp steamer'? African Journal of AIDS Research 5(2): 159-166.

Chilisa, B., P. Bennel and K. Hyde. 2001. The impact of HIV/AIDS on the University of Botswana: Developing a comprehensive strategic response. http://ageconsearch.umn.edu/bitstream/ 12879/1/er010044.pdf (accessed 12 March 2015).

Craig, I. K., X. Xia and J. W. Venter. 2004. Introducing HIV/AIDS education into the electrical engineering curriculum at the University of Pretoria. IEEE Transactions on Education 47(1): 6573.

Davis, R. 2008. HIV/AIDS education: Still an important issue for veterinarians. Public Health Reports 123(3): 266-275.

De Lange, N. 2014. The HIV and AIDS academic curriculum in higher education. South African Journal of Higher Education 28(2): 368-385.

Douglas, N., I. Warwick, G. Whitty and P. Aggleton. 2000. Vital youth: Evaluating a theatre in health education project. Health Education 100(5): 207-215.

Elkana, Y. 2009. Freedom and interdisciplinarity: The future of the university curriculum. Social Research 76(3): 933-942.

Ergene, T., F. Cok, A. Tumer and S. Unal. 2005. A controlled study of preventive effects of peer education and single-session lectures on HIV/AIDS knowledge and attitudes among university students in Turkey. AIDS Education and Prevention 17(3): 268-278.

Fisher, J. D. and W. A. Fisher. 2000. Theoretical approaches to individual-level change in HIV risk behavior. In Handbook of HIV prevention, ed. L. Peterson and C. C. Di Clemente, 3-55. New York: Kluwer Academic/Plenum Press.

Francis, D. A. 2010. Sexuality education in South Africa: Three essential questions. International Journal of Educational Development 30(3): 314-331.

Fricker, M. 2007. Epistemic injustice: Power and the ethics of knowing. New York: Oxford.

Giuliani, M., M. Tumbarello, M. Marino et al. 2011. Dental hygienists behavior towards HIV-positive patients in highly active antiretroviral therapy era: A pilot survey. International Journal of Dental Hygiene 9(3): 204-210.

HEAIDS. 2008. Policy and strategic framework on HIV and AIDS for higher education. Pretoria: HESA

HEAIDS. 2010a. HIV and AIDS in teacher education. Evaluation report of a pilot project in South African higher education institutions. Pretoria: HESA. http://heaids.files.wordpress.com/ 2012/10/03-4979-hesa-hiv-and-aids-in-teacher-education-cs4.pdf (accessed 8 April 2016).

HEAIDS. 2010b. Creating space for HIV and AIDS in the curriculum: Rapid assessment of curricular responses. Pretoria: HESA.

Holderness, W. L. B. 2012. Equipping educators to address HIV and AIDS: A review of selected teacher education initiatives. Journal of Social Aspects of HIV/AIDS 9(1): 48-55.

Jafari, A., R. Yazdani, M. R. Khami, M. Mohammadi, and M. Hajiabdolbaghi. 2012. Effect of an educational course at an Iranian Dental School on students' knowledge of and attitudes about HIV/AIDS. Journal of Dental Education 76(6): 792-799.

Lesko, N. 2007. University teaching and social cohesion in the age of AIDS: A South African case 
study. Prospects 37(1): 333-344.

Mak, W. W. S and J. W. Y. Yiu. 2010. Effectiveness of knowledge-contact program in improving nursing students' attitudes and emotional competence in serving PHA. Social Science Medicine 71(1): 38-44.

McGinty, S. and K. Mundy. 2009. HIV/AIDS educators: The challenges and issues for Namibian bachelor of education students. Teaching and Teacher Education 25: 141-148.

McLean, M. and L. Hiles. 2005. Introducing HIV and AIDS education into the first year of a problembased learning curriculum: A template for health science education: Research. Health $S A$ Gesondheid 10(2): 17-23.

Montano, D. and D. Kasprzyk, D. 2002. The theory of reasoned action and the theory of planned behavior. In Health behavior and health education: Theory, research, and practice, ed. K. Glanz, B. K. Rimer and F. M. Lewis, 67-99. San Francisco: Jossey-Bass.

Morrell, R. 2003. Silence, sexuality and HIV/AIDS in South African schools. The Australian Educational Researcher 30(1): 41-61.

Mugimu, C. B. and R. Nabadda. 2009. The role of pre-service and in-service teacher training (PITT) programmes in preparing teachers for HIV curriculum integration. Prospects 39: 383-397.

Munro, S., S. Lewin, T. Swart and J. Volmink. 2007. A review of health behaviour theories: How useful are these for developing interventions to promote long-term medication adherence for TB and HIV/AIDS? BMC Public Health 7(1): 104.

Obregon, C. O. A. R. 2000. A critical assessment of theories/models used in health communication for HIV/AIDS. Journal of Health Communication 5(sup1): 5-15.

Otaala, B. 2006. African tertiary institutions' response to the HIV/AIDS epidemic: Current practices and the way forward. In Humanising pedagogy through HIV and AIDS prevention, ed. C. A. Grant and L. M. Summerfield, 97-110. Boulder, Colorado: Paradigm.

Petersen, I., A. Bhagwanjee, A. Bhana and Z. Mahintsho. 2004. The development and evaluation of a manualised participatory HIV/AIDS risk reduction programme (sex and risk) for tertiary level learners: A pilot study. African Journal of AIDS Research 3(1): 93-100.

Petersen, N., J. de Beer and H. Dunbar-Krige. 2011. Use of a simulation game for HIV/AIDS education with pre-service teachers. African Journal of AIDS Research 10(1): 73-81.

Risner, D. 2002. Sexual orientation and male participation in dance education: Revisiting the open secret. Journal of Dance Education 2(3): 84-92.

Risner, D. and S. Thompson. 2005. HIV/AIDS in dance education a pilot study in higher education. Journal of Dance Education 5(2): 70-76.

Rohn, E. R., A. Sankar, D. C. Hoelscher, M. Luborsky and M. H. Parise. 2006. How do socialpsychological concerns impede the delivery of care to people with HIV? Issues for dental education. Journal of Dental Education 70(10): 1038-1042.

Rowan, D. and J. Shears. 2011. HIV/AIDS course content in CSWE-accredited social work programs: A survey of current curricular practices. Journal of Teaching in Social Work 31: 119-130.

Seacat, J. D., M. D. Litt and D. S. Daniels. 2009. Dental students treating patients living with HIV/AIDS: The influence of attitudes and HIV knowledge. Journal of Dental Education 73(4): 437-44.

Semali, L. 2006. Postcolonial perspectives in constructing teacher knowledge about HIV/AIDS. In Humanising pedagogy through HIV and AIDS prevention, ed. C. A. Grant and L. M. Summerfield, 97-110. Boulder, Colorado: Paradigm.

SIDA see Swedish International Development Cooperation Agency.

Sogren, M., A. Jones, K. Nathaniel and J. Cameron-Padmore. 2012. Reconfiguring social work education to fight HIV-AIDS: A model for developmental contexts. Social Work Education: The International Journal 31(7): 880-895.

Swedish International Development Cooperation Agency. 2005. SIDA's response framework to 
HIV/AIDS in education position paper 2005. Stockholm: SIDA Education Division.

Tamale, S. 2012. Interrogating the link between gendered sexualities, power and legal mechanisms: Experiences from the lecture room. In, Third Degree, AIDS review, ed. C. Volks, 49-60. Pretoria: University of Pretoria.

Themane, M. J. and M. J. Taole. 2013. Student-teachers' HIV/AIDS knowledge and their risky sexual behaviour at a South African rural-based university. African Journal for Physical, Health Education, Recreation and Dance (AJPHERD) 19(3): 527-540.

UNAIDS, World Bank and UNDP. 2005. Mainstreaming HIV/AIDS in sectors and programs - an implementation guide for national responses. http://www.undp.org/hiv/docs/Mainstreaming B\%5B1\%5D.pdf (accessed 24 June 2015).

UNESCO. 2008. EDUCAIDS Framework for Action. 2nd Ed. http://unesdoc.unesco.org/images/ 0014/001473/147360E.pdf (accessed 13 May 2015).

Van Laren, L. 2007. Using metaphors to integrating HIV and AIDS education in a mathematics curriculum in pre-service teacher education: An exploratory classroom study. International Journal of Inclusive Education 11: 461-481.

Van Laren, L. 2008. Exploration of strategies to integrate HIV and AIDS education in pre-service teacher education. African Journal of Research in Mathematics, Science and Technology Education 12(1): 47-61.

Van Laren, L. 2012. Using HIV\&AIDS statistics in pre-service Mathematics Education to integrate HIV\&AIDS education. SAHARA-J: Journal of Social Aspects of HIV/AIDS 9(1): 11-18.

Van Laren, L., N. de Lange and P. Tanga. 2013. ‘Breaking out of the cocoon': Academics' experiences of integrating HIV and AIDS into the curriculum. Acta Academia 45(3): 291-317.

Van Wyk, B. and J. Pieterse. 2006. Institutional responses to HIV/AIDS from institutions of Higher Education in the Southern African development community. Southern African Regional Universities Association (SARUA). Pretoria: University of Pretoria. http://www.sarua.org/files/ publications/SARUA_HEI_HIV_AIDS_Study.pdf (accessed 12 March 2015).

Webb, P. and A. Gripper. 2010. Developing teacher self-efficacy via a formal HIV/AIDS intervention. SAHARA-J: Journal of Social Aspects of HIV/AIDS 7(3): 28-31.

Williams, A. B., H. Wang, J. Burgess, C. Wu, Y. Gong and Y. Li. 2006. Effectiveness of an HIV/AIDS educational programme for Chinese nurses. Issues and Innovations in Nursing Education 56(3): $710-720$.

Wilmot, D. and L. Fraenkel. 2009. Swampfire: An HIV/AIDS simulation for enabling learning about risk and vulnerability. Paper presented at Future of the Consumer Society. 28-29 May, Tampere, Finland.

Wilmot, D. and L. Wood. 2012. In search of an enabling pedagogy for HIV and AIDS education in initial teacher education. South-African Journal for Higher Education 26(5): 1112-1130.

Wood, L. A. 2009. 'Not only a teacher, but an ambassador': Facilitating HIV/AIDS educators to take action. African Journal of Aids Research 8(1): 83-92.

Wood, L. 2011a. Faculty views of HIV and AIDS education in the curriculum at tertiary level. South African Journal of Higher Education 25(4): 819-837.

Wood, L. 2011b. HIV and AIDS education in pre-service teacher programmes: Lessons learned from experience in a Post-Graduate Certificate in Education. Acta Academica 43(4): 181-202.

Wood, L. 2012. 'Every teacher is a researcher!': Creating indigenous epistemologies and practices for HIV prevention through values-based action research. SAHARA-J: Journal for Social Aspects of HIV and AIDS Research Alliance 9(Sup 1): 19-27.

Wood, L. 2013. Dealing with HIV and AIDS in the classroom. Cape Town: Juta.

Zaninovic, P., Z. S. Natto, R. L. Turner, G. A. Toledo, G. Graciela, G. G. Duran, J. R. Trott and T. Rogers. 2013. An innovative HIV training program for dental hygiene students. The Journal of Dental Hygiene 87(1): 47-55. 
